\title{
Micronodules and emphysema in coal mine dust or silica exposure: relation with lung function
}

\author{
P.A. Gevenois*,, G. Sergent*, V. De Maertelaer+, F. Gouat*, J-C. Yernault**, P. De Vuyst**,*
}

Micronodules and emphysema in coal mine dust or silica exposure: relation with lung function. P.A. Gevenois, G. Sergent, V. De Maertelaer, F. Gouat, J-C. Yernault, P. De Vuyst. COERS Journals Ltd 1998.

ABSTRACT: The aim of this study was to investigate the respective effects of micronodules and pulmonary emphysema, detected by computed tomography (CT), on lung function in workers exposed to silica and coal mine dust.

Eighty-three subjects exposed to silica $(n=35)$ or to coal mine dust $(n=48)$, without progressive massive fibrosis, were investigated by high-resolution and conventional CT scans to detect micronodules and to quantify pulmonary emphysema by measuring the relative area of the lung with attenuation values lower than -950 Hounsfield units.

Sixty-six (54.5\%) subjects had evidence of micronodules on CT scans. Smokers had micronodules more rarely than nonsmokers. Significant correlations were found between the forced expiratory volume in one second (FEV1; \% predicted) $(r=-0.41$, $\mathrm{p}<0.001), \mathrm{FEV} 1 /$ vital capacity $(\mathrm{VC})(\mathrm{r}=-\mathbf{0 . 6 1}, \mathrm{p}<0.001)$, diffusing capacity of the lung for carbon monoxide $(D \mathrm{~L}, \mathrm{CO})(\mathrm{r}=\mathbf{- 0 . 3 6}, \mathrm{p}<0.001)$ and the extent of emphysema. No difference was demonstrated in the linear relationships between the extent of emphysema and the pulmonary function according to the type of exposure or the presence of micronodules on CT scans.

This study suggests that micronodules detected by computed tomography have no influence, by themselves, on pulmonary function and that they should only be considered as a marker of exposure.

Eur Respir J 1998; 12: 1020-1024.
Depts of *Radiology and **Chest Medicine, Hôpital Erasme, and +Statistical Unit, IRIBHN, Université Libre de Bruxelles, Brussels, Belgium. ‡Occupational Disease Fund, Brussels, Belgium.

Correspondence: P.A. Gevenois

Dept of Radiology

Hôpital Erasme

Route de Lennik 808

1070 Brussels

Belgium

Fax: 3225554545

Keywords: Chronic obstructive pulmonary disease

coal mine dust

computed tomography

emphysema

silica

silicosis

Received: March 101998

Accepted after revision August 91998
Computed tomography (CT) is now considered as a standard of reference in the noninvasive detection of pneumoconiosis and has gained increasing importance in medicolegal evaluations [1-3]. Low grades are characterized by micronodules that consist of small, rounded opacities $<7 \mathrm{~mm}$ in diameter [1]. When these opacities are detected in exposed workers, functional impairment is considered as related to pneumoconiosis and compensated for as such. Nevertheless, the effects on lung function of these micronodules detected on CT scans are not known.

Pathological material is considered the most appropriate way in which to investigate the relationships between functional abnormalities and diseases. Nevertheless, specimens obtained from surgery and from autopsy may not reflect adequately the disease process: surgical specimens consisting of only one lobe or one lung may not reflect the overall extent of pneumoconiosis and emphysema, and post mortem studies often entail a long interval between physiological testing and death. Moreover, surgical studies only include patients with mild disease, whereas autopsy studies include patients with severe disease. Autopsy as well as CT studies have previously evaluated the relationships between dust exposure, pneumoconiosis, tobacco smoking and pulmonary emphysema [4-10], but as far as we know, no study has specifically compared the respective influences of micronodules and of pulmonary emphy- sema detected by CT on lung function parameters. In order to evaluate this, combined reading of conventional and thin-section CT scans for the detection of pneumoconiosis was used because it has been shown that both techniques are complementary in increasing the sensitivity of the method [11]. Emphysema was quantified in vivo using an objective CT procedure that had been validated previously by comparison with histopathological data $[12,13]$.

\section{Materials and methods}

\section{Subjects}

Workers seeking compensation for possible pneumoconiosis are examined at the Belgian Occupational Disease Fund by both an occupational and a chest physician for medical and occupational history. They receive a medical evaluation including pulmonary function tests and they undergo chest radiography. Furthermore, the reality of exposure to fibrogenic dust is assessed by enquiries made by engineers. The chest radiograph is graded for profusion, size and shape of small opacities by three trained pneumologists according to the 1980 International Labour Office (ILO) Classification [14]. They have extensive experience 
working with the ILO Classification, reading several hundred radiographs per year. If the profusion score is $\breve{S} 1 / 1$ for the three readers, the pneumoconiosis is acknowledged and compensated for according to the impairment measured in the pulmonary function tests and radiographic abnormalities. If the profusion score from at least one reader is $<1 / 1$, a CT scan of the chest is requested. CT scans are also requested to confirm that a lesion detected on plain film is really $>1 \mathrm{~cm}$ in diameter and may consequently be considered as progressive massive fibrosis (PMF), as defined in the 1980 ILO Classification [14].

For the purpose of the present study, the CT examinations requested by the Belgian Occupational Disease Fund during 4 yrs were considered. All of these CT examinations were requested in order to demonstrate CT lung signs compatible with coal worker's pneumoconiosis (CWP) and silicosis as well as associated PMF. Nevertheless, patients with PMF revealed by CT scan were rejected from the study sample. Therefore, all the subjects included in the present study had been exposed to dust, were suspected of having low-grade pneumoconiosis (profusion score $<1 / 1$ ), or had well-established pneumoconiosis but no PMF.

These exposed workers consisted of 83 subjects ( 82 males and one female), ranging in age 42-77 yrs (mean age \pm SEM $58 \pm 1$ yrs). Sixty-five subjects were referred in order to detect possible pneumoconiosis. In 18 others, the CT scan was requested in order to exclude possible PMF. Forty-eight subjects were exposed in coal mines in Belgium and 35 subjects were exposed to silica in other industries such as steel foundries, quarries and sandblasting. The duration of exposure ranged 1-46 yrs (mean \pm SEM $17 \pm$ $1 \mathrm{yrs}$ ), but only four subjects had been exposed for $<5 \mathrm{yrs}$. The duration of exposure ranged 1-38 yrs (mean \pm SEM $14 \pm$ $1 \mathrm{yrs}$ ) in the coal miners and 2-46 yrs (mean \pm SEM $20 \pm 1$ yrs) in the other silica-exposed workers. Twenty-six subjects were current smokers and had smoked for $32 \pm 4$ packyrs (mean \pm SEM) and 29 were exsmokers and had smoked for $27 \pm 4$ pack-yrs, while 16 were nonsmokers. The smoking habits were unknown in 12 subjects. Workers exposed to coal mine dusts were significantly older than those exposed to silica $(59 \pm 1$ versus $55 \pm 1$ yrs, $\mathrm{p}=0.008)$ and were exposed during a significantly shorter period $(14 \pm 1$ versus $20 \pm 1 \mathrm{yrs}, \mathrm{p}=0.003)$, but for the smokers, their smoking consumptions were not significantly different $(33 \pm 4$ and $26 \pm 3$ pack-yrs, respectively, $\mathrm{p}=0.183$ ).

In addition, these exposed subjects were compared with a reference group of patients, not exposed to dust, and enrolled in the previous studies in which we demonstrated that the relative area of lung with attenuation values $<-950$ Hounsfield units (HU) is a measure of emphysema [12, 13] and that this area correlates significantly with functional measurements of airflow obstruction [15]. This sample consisted of 40 patients (32 males and eight females), with ages ranging 40-77 yrs (mean age \pm SEM $60 \pm 1 \mathrm{yrs}$ ). One of these patients was a nonsmoker, 12 were exsmokers and 27 were current smokers. The smokers had smoked $47 \pm 4$ pack-yrs.

\section{Pulmonary function tests}

The static and dynamic lung volumes were measured with a spirometer (Gould Godart, Bilthoven, the Netherlands) and the diffusing capacity of the lung for carbon monoxide ( $D \mathrm{~L}, \mathrm{CO})$ was measured by the single-breath method (Transferscreen II; Jaeger, Würzburg, Germany) in 77 of the 83 subjects. The measured values were compared to the predicted normal values established by the European Community of Coal and Steel $[16,17]$.

\section{Standard radiography}

Standard posteroanterior radiographs were taken at maximal inspiration. As mentioned previously, the chest radiographs were graded by three readers according to the 1980 ILO Classification [14]. These readers were not involved in the CT assessment and were not aware of the CT results. For each film, profusion was summarized by taking the median of the three readers' combined small opacity profusion categories. Finally, the study sample was arbitrarily divided into two groups according to a median score of $<1 / 1$ or $\breve{S} 1 / 1$.

\section{Computed tomography}

In exposed workers, the CT examinations consisted of conventional $10 \mathrm{~mm}$ collimation scans obtained at $10 \mathrm{~mm}$ intervals from the lung apices to bases $(120 \mathrm{kV}$ peak, 210 $\mathrm{mA}$, scanning time $1 \mathrm{~s}$ ) and $1 \mathrm{~mm}$ collimation scans obtained at $25 \mathrm{~mm}$ intervals (137 kVpeak, $255 \mathrm{~mA}$, scanning time $1 \mathrm{~s}$ ). In unexposed patients, the CT examination consisted of $1 \mathrm{~mm}$ collimation scans obtained at $10 \mathrm{~mm}$ intervals from the lung apices to bases ( $137 \mathrm{kV}$ peak, 255 $\mathrm{mA}$, scanning time $1 \mathrm{~s})[12,13]$. CT scans were performed using a Siemens Somatom Plus scanner (Siemens AG, Erlangen, Germany) during breath-holding after deep inspiration in the supine position [3]. No subjects received i.v. contrast medium.

The CT scans were read independently for the presence of micronodules by two experienced chest radiologists. Discrepancies and ambiguous findings were discussed until consensus was reached. Micronodules were arbitrarily defined as lesions of $ð 7 \mathrm{~mm}$ in diameter, since CT does not allow distinction between coal dust macules, mixed dust and silicotic nodules [1]. Since BéGin et al. [2] showed that the inter-reader variability was significantly reduced despite the absence of ILO-type films for the CT scans, the inter-reader variability was not assessed. The radiologists were not aware of either the chest radiograph results or the pulmonary function tests (PFT). The profusion of micronodules on CT scans was not scored since there are no validated standards for $\mathrm{CT}$ scans.

The Pulmo CT® software from Siemens [18] was used to measure the lung area on the thin-section CT scans with attenuation values <-950 HU. This is expressed as a percentage of the total lung area (RA950) and is a reflection of the extent of the pulmonary emphysema $[12,13]$.

\section{Statistical analysis}

Pearson Chi-squared tests (exact p-value method) were used for comparing proportions between groups. Comparisons of two means were performed with Student's t-tests.

Relationships between the PFT and RA950 were investigated with multiple linear regressions. The forced expiratory volume in one second (FEV $1 ; \%$ predicted), FEV1/ 
vital capacity (VC; \% pred) and DL,CO (\% pred) were successively considered as the dependent variable. The independent variables were the RA950, a new indicator variable and the interaction (i.e. product) of these two variables. The indicator variable is coded as 0 or 1 . For example, to detect a possible effect of smoking on the relationship between a PFT response and RA950, an indicator variable, tobacco (Tob), was introduced, set to 1 for the smoking or exsmoking subjects and to 0 for the nonsmoking subjects. The model becomes:

\section{$\mathrm{PFT}=a+b \cdot \mathrm{RA} 950+c \cdot \mathrm{Tob}+d \cdot \mathrm{RA} 950 \times \mathrm{Tob}$}

This equation includes two possible forms according to the value of Tob $(0$ or 1$)$, i.e. PFT $=a+b \cdot \mathrm{RA} 950$ for the nonsmoking subjects and PFT $=a+c+(b+d)$. RA950 for the smoking ones. A statistically significant $c$ coefficient represents a difference in the intercepts of the two corresponding straight lines, these intercepts being equal to $a$ for the nonsmoking group and to $(a+c)$ for the smoking group. A statistically significant $d$ coefficient represents a difference in their slopes, which are $b$ for the nonsmoking and $(b+d)$ for the smoking group. Similar procedures were used to detect a possible effect of type of exposure and to put forward a possible difference between workers with micronodules on CT scans, those without micronodules on CT scans and unexposed subjects.

\section{Results}

On chest radiography, $56(67.5 \%)$ workers had a median profusion score of $<1 / 1$ and $27(32.5 \%)$ of Š $1 / 1$. On CT scan, $46(54.5 \%)$ subjects had evidence of micronodules and $37(45.6 \%)$ subjects had no micronodules. The correspondence between the median profusion score on the chest radiographs $(<1 / 1$ and $\breve{S} 1 / 1)$ and the detection of micronodules on the CT scans was statistically significant $(\mathrm{p}=0.0002)$ (table 1), but up to 23 of $46(50 \%)$ subjects with a positive CT scan had a profusion score of small opacities on the chest radiograph of $<1 / 1$. Only four of 37 (11\%) workers with no micronodules on CT scans had a profusion score S $1 / 1$.

In exposed workers, smokers had micronodules detected by CT scans more rarely and nonsmokers showed micronodules on CT scans more frequently (table 2 ). This difference was statistically significant $(\mathrm{p}=0.038)$, suggesting at least, that micronodules cannot be explained by smoking alone.

The RA950 (mean \pm SD) was $5.9 \pm 5.3 \%$ and ranged from $0.1-27.0 \%$ in the exposed workers. The results of the PFT and the Pearson's correlation coefficients between the RA950 and the PFT results are listed in table 3. The RA950 $($ mean \pm SD) was $9.5 \pm 8.0 \%$ and ranged from $0.5-30.5 \%$ in the unexposed patients. The results of the PFT and the

Table 1. - Small opacity profusion categories on chest radiography and the presence of micronodules on computed tomographic scans

\begin{tabular}{|c|c|c|c|}
\hline & \multicolumn{2}{|c|}{ Profusion score } & \multirow[t]{2}{*}{ Total } \\
\hline & $<1 / 1$ & Š1/1 & \\
\hline Micronodules & 23 & 23 & 46 \\
\hline No micronodules & 33 & 4 & 37 \\
\hline Total & 56 & 27 & 83 \\
\hline
\end{tabular}

Values are numbers of subjects.
Table 2. - Smoking habits and the presence of micronodules on computed tomographic scans

\begin{tabular}{lccc}
\hline & Smokers & Nonsmokers & Total \\
\hline Micronodules & 25 & 12 & 37 \\
No micronodules & 30 & 4 & 34 \\
Total & 55 & 16 & 71 \\
\hline
\end{tabular}

Values are numbers of subjects.

Pearson's correlation coefficients between the RA950 and the PFT results are listed in table 4.

When the exposed workers were divided according to the type of exposure, no significant difference was observed in the RA950 or in the results of the PFT. The regression lines linking $\mathrm{FEV}_{1}\left(\%\right.$ pred), $\mathrm{FEV}_{1} / \mathrm{VC}$ (\% pred) and $D \mathrm{~L}, \mathrm{CO}(\%$ pred) to RA950 were compared by adding a further variable expressing the type of exposure (coal mine dust or silica). No significant difference was observed according to the type of exposure.

When the exposed workers were divided according to their smoking habits, no significant difference was observ-ed between smokers and nonsmokers in the RA950 or in the results of the PFT, except for $D \mathrm{~L}, \mathrm{CO}(\mathrm{p}=0.026)$. The regression lines linking FEV1 (\% pred), FEV1/VC ( $\%$ pred) and DL,CO (\% pred) to RA950 were compared by adding a further variable expressing the smoking habits (smokers or nonsmokers). Taking into account this new variable together with the RA950 results in a decrease in the strength of the relationships between PFT results and RA950 observed when RA950 was the only independent variable. The only significant effect of this was a decrease in $\mathrm{FEV} 1 / \mathrm{VC}$ (\% pred) values with increasing RA950 ( $\mathrm{p}=$ 0.011 ), with no significant difference according to the smoking habits.

Finally, when the exposed workers were divided according to the presence of micronodules on CT scans, no statistical difference was seen in either the RA950 or the results of the PFT. The regression lines linking FEV1 (\% pred), $\mathrm{FEV}_{1} / \mathrm{VC}$ (\% pred) and $\mathrm{DL}, \mathrm{CO}(\%$ pred) to RA950 were compared between workers without and workers with micronodules on CT scans and between workers without micronodules and unexposed patients. A statistically significant decrease in each of these PFT responses with RA950 was observed (each at $\mathrm{p}<0.003$ ), but these relationships did not differ significantly between these groups.

Table 3. - Results of pulmonary function tests (PFT) and Pearson correlation coefficients for the relation between PFT results and RA950 in exposed workers

\begin{tabular}{lclcl}
\hline & Mean \pm SD & Range & $\mathrm{r}$ & \multicolumn{1}{c}{$\mathrm{p}$} \\
\hline VC \% pred & $80 \pm 13$ & $43-108$ & 0.004 & $>0.05$ \\
TLC \% pred & $94 \pm 15$ & $51-137$ & 0.21 & $>0.05$ \\
FEV1 \% pred & $75 \pm 21$ & $24-121$ & -0.41 & $<0.001$ \\
RV \% pred & $126 \pm 36$ & $60-221$ & 0.34 & $<0.01$ \\
FEV1/VC \% & $67 \pm 14$ & $32-90$ & -0.61 & $<0.001$ \\
FEV1/VC \% pred & $87 \pm 17$ & $41-116$ & -0.61 & $<0.001$ \\
RV/TLC \% & $38 \pm 8$ & $24-60$ & 0.35 & $<0.01$ \\
DL,CO \% pred & $81 \pm 22$ & $34-130$ & -0.36 & $<0.001$
\end{tabular}

RA950: relative area of lung with attenuation values $<-950 \mathrm{Hou}-$ nsfield units; VC: vital capacity; \% pred: percentage of the predicted value; TLC: total lung capacity; FEV1: forced expiratory volume in one second; RV: residual volume; $D \mathrm{~L}, \mathrm{CO}$ : diffusing capacity of the lung for carbon monoxide. The predicted values proposed by the Working Party of the European Community for Steel and Coal [16] were used. 
Table 4. - Results of pulmonary function tests (PFT) and Pearson correlation coefficients for the relation between PFT results and RA950 in unexposed workers

\begin{tabular}{lrlrl}
\hline & Mean \pm SD & Range & \multicolumn{1}{c}{$\mathrm{r}$} & $\mathrm{p}$ \\
\hline VC \% pred & $94 \pm 16$ & $44-128$ & -0.37 & $<0.05$ \\
TLC \% pred & $116 \pm 24$ & $74-220$ & 0.36 & $<0.05$ \\
FEV1 \% pred & $74 \pm 20$ & $13-109$ & -0.62 & $<0.001$ \\
RV \% pred & $164 \pm 81$ & $76-551$ & 0.46 & $<0.01$ \\
FEV1/VC \% & $61 \pm 12$ & $22-87$ & -0.69 & $<0.001$ \\
FEV1/VC \% pred & $78 \pm 15$ & $28-111$ & -0.71 & $<0.001$ \\
RV/TLC \% & $48 \pm 13$ & $26-87$ & 0.45 & $<0.01$ \\
DL,CO \% pred & $66 \pm 19$ & $21-102$ & -0.56 & $<0.001$ \\
\hline
\end{tabular}

RA950: relative area of lung with attenuation values $<-950 \mathrm{Hou}-$ nsfield units; VC: vital capacity; \% pred: percentage of the predicted value; TLC: total lung capacity; FEV1: forced expiratory volume in one second; RV: residual volume; $D$ L,CO: diffusing capacity of the lung for carbon monoxide. The predicted values proposed by the Working Party of the European Community for Steel and Coal [16] were used.

\section{Discussion}

In the present study, micronodules compatible with lowgrade pneumoconiosis were detected by CT scan in up to half of subjects with a profusion score for small opacities on the chest radiograph $<1 / 1$. The low sensitivity of the chest radiograph for detecting mild grades of CWP and lesions of PMF is an important limitation of this technique [19]. CT has been shown to be more sensitive than chest radiography in detecting pulmonary opacities compatible with the diagnosis of pneumoconiosis. Thus, this imaging modality is used in the medicolegal evaluation of workers seeking compensation [1-3]. Previous studies comparing chest radiography and combined reading of conventional and thin-section $\mathrm{CT}$ scans have reported results ranging from $18-40 \%$ of workers with a profusion radiographic score $<1 / 1$ [1-3]. The small opacities were scored on radiographs according to the 1980 ILO Classification, whereas the micronodules visible on CT scans were only coded as present or absent since there is no validated classification of profusion of opacities on CT scans. Nevertheless, the specificity of these opacities is unknown since micronodules have been described in various disorders, including as an effect of cigarette smoking [20, 21]. Since, in the present study, smokers more rarely had micronodules and nonsmokers more frequently had micronodules, the micronodules detected by CT scan were, at least in the major part of this study group, not related to smoking but to dust-induced abnormalities. The mean duration of exposure was also consistent with the diagnosis of pneumoconiosis.

When the study population was divided according to smoking habits, as expected, a significantly lower DL,CO was found in smokers than in nonsmokers [17]. Although the $\mathrm{FEV} 1 / \mathrm{VC}$ ratio was lower in smokers than in nonsmokers, the difference did not reach statistical significance, probably because of the relatively small population size and the wide ranges of values. In addition, when the study group was divided according to the type of exposure, no statistically significant difference was found in either the extent of emphysema or lung function abnormalities between workers exposed to silica or coal mine dust.

More interestingly, no difference in either the extent of emphysema or lung function abnormalities was observed according to the presence or absence of micronodules on CT scans. The present study, thus shows that in workers exposed to silica or coal mine dust, as well as in unexposed patients, the expiratory airflow limitation correlates negatively with the extent of pulmonary emphysema, but that the relationships between the RA950 and the pulmonary function parameters that were measured did not differ according to smoking or not, or to the presence of micronodules detected by CT. The extent of emphysema, whatever its cause, is thus the major determinant of the impaired lung function. These findings are consistent with those of ColLins et al. [22], showing that pulmonary function did not differ between coal miners with or without nodules detected by thin-section CT. However, they did not consider diffusing capacity, and although it is recommended to use thin as well as thick CT sections to detect micronodules, they used only thin sections [1-3].

In pulmonary emphysema, the proportion of pixels with the lowest attenuation values on CT scans increases as a result of the relative reduction in blood and tissue accompanied by a subsequent relative increase in air [23]. Consequently, the relative area of lung with attenuation values lower than a given threshold should be an index of emphysema. By complementary approaches based on macroscopic and microscopic comparisons, respectively, it was previously demonstrated that RA950 appeared to be a method which allows an objective quantification of macroscopic emphysema and also a reflection of microscopic emphysema [12,13]. This method does not define emphysema, but as commented by MüLLER and THURLBECK [24], it may be accepted that this technique "allows reasonably accurate objective quantification of the extent of pulmonary emphysema". Nevertheless, the strongest relationship between RA950 and morphometric references concerned macroscopic emphysema and the sensitivity of this technique for detecting early microscopic emphysema is not known. Nevertheless, the aim of the present study was not to make an accurate diagnosis of pulmonary emphysema but to compare the extent of emphysema between groups of workers.

This study tends to confirm that simple pneumoconiosis by itself has no effect on lung function as detected by CT. Pneumoconiotic micronodules detected by CT correspond to dust deposits with more or less fibrotic reaction at the level of respiratory bronchioles, where particle deposition is maximal [25]. This kind of small airways lesion can exist without airflow limitation detected by classical manoeuvres (FEV1 and FEV1/VC), which are more likely to reflect preacinar airway alterations. Morphological changes at the level of the respiratory bronchioles can, however, be associated with abnormalities of other indices such as inert gas washout tests when the $\mathrm{FEV}_{1} / \mathrm{VC}$ ratio is within the normal range $[26,27]$. These tests were not performed on the workers in the present study.

Occupational exposure to coal mine dust or silica dust could have an adverse effect on PFT, independently of the presence of CT evidence of pneumoconiosis [25, 28]. Medicolegal experts and compensation boards or organizations should be aware that a decision to compensate lung function abnormalities only on the basis of the presence of micronodules on CT scans has no scientific basis. In other words, since the functional impairment does not depend on the micronodules detected by $\mathrm{CT}$ scans, the search for 
their presence in workers with a normal chest radiograph or low radiological grades according to the 1980 ILO Classification seems to have little relevance for a decision on compensation.

In conclusion, although the present study concerns a population selected on the basis of referral for possible compensation and is neither a cross-sectional nor a cohort epidemiological study, it suggests that the micronodules detected by the combined reading of conventional and thinsection computed tomographic scans in exposed workers with no progressive massive fibrosis do not, by themselves, have an influence on pulmonary function and that they should only be considered as a marker of exposure.

\section{References}

1. Remy-Jardin M, Degreef JM, Beuscart R, Voisin C, Remy J. Coal worker's pneumoconiosis: CT assessment in exposed workers and correlation with radiographic findings. Radiology 1990; 177: 363-371.

2. Bégin R, Ostiguy G, Filion R, Colman N. Computed tomography scan in the early detection of silicosis. Am Rev Respir Dis 1991; 144: 697-705.

3. Gevenois PA, Pichot E, Dargent F, Dedeire S, Vande Weyer R, De Vuyst P. Low grade coal worker's pneumoconiosis. Acta Radiol (Diagn) 1994; 35: 351-356.

4. Ruckley VA, Gauld SJ, Chapman JS, et al. Emphysema and dust exposure in a group of coal workers. Am Rev Respir Dis 1984; 129: 528-532.

5. Becklake MR, Irwig L, Kielkowski D, Webster I, De Beer M, Landau S. The predictor of emphysema in South African gold miners. Am Rev Respir Dis 1987; 35: 12341241.

6. Kinsella M, Müller NL, Vedal S, Staples C, Abboud RT, Chan-Yeung M. Emphysema in silicosis: a comparison of smokers with nonsmokers using pulmonary function testing and computed tomography. Am Rev Respir Dis 1990; 141: 1497-1500.

7. Hnizdo E, Sluis-Cremer GK, Abramowitz JA. Emphysema type in relation to silica dust exposure in South African gold miners. Am Rev Respir Dis 1991; 143: 1241-1247.

8. Cowie RL, Hay M, Thomas RG. Association of silicosis, lung dysfunction, and emphysema in gold miners. Thorax 1993; 48: 746-749.

9. Hnizdo E, Sluis-Cremer GK, Baskind E, Murray J. Emphysema and airway obstruction in nonsmoking South African gold miners with long exposure to silica dust. Occup Environ Med 1994; 51: 557-563.

10. Bégin R, Filion R, Ostiguy G. Emphysema in silica- and asbestos-exposed workers seeking compensation: a CT scan study. Chest 1995; 108: 647-655.

11. Remy-Jardin M, Remy J, Deffontaines C, Duhamel A. Assessment of diffuse infiltrative lung disease: comparison of conventional CT and high resolution CT. Radiology 1991; 181: 157-162.

12. Gevenois PA, de Maertelaer V, De Vuyst P, Zanen J, Yernault JC. Comparison of computed density and macroscopic morphometry in pulmonary emphysema. Am J
Respir Crit Care Med 1995; 152: 653-657.

13. Gevenois PA, De Vuyst P, de Maertelaer V, et al. Comparison of computed density and microscopic morphometry in pulmonary emphysema. Am J Respir Crit Care Med 1996; 154: 187-192.

14. International Labour Organization. Guidelines for the used of ILO International Classification of Radiographs of Pneumoconioses. Rev Edn. International Labour Office Safety and Health Series no. 22 (Rev 80). Geneva, International Labour Office, 1980.

15. Gevenois PA, De Vuyst P, Sy M, et al. Pulmonary emphysema: quantitative CT during expiration. Radiology 1996; 199: 825-829.

16. Quanjer P, Tammeling GJ, Cotes JE, Pedersen OF, Peslin $\mathrm{R}$, Yernault JC. Lung volumes and forced ventilatory flows. Eur Respir J 1993; 6: Suppl. 16, 5-40.

17. Cotes JE, Chinn DJ, Quanjer PH, Roca J, Yernault JC. Standardization of the measurment of transfer factor (diffusing capacity). Eur Respir J 1993; 6: Suppl. 16, 41-42.

18. Kalender WA, Fichte H, Bautz W, Skalej M. Semiautomatic evaluation procedures for quantitative $\mathrm{CT}$ of the lung. J Comput Assist Tomogr 1991; 15: 248-255.

19. Vallyathan V, Brower PS, Green FHY, Attfield MD. Radiographic and pathologic correlation of coal worker's pneumoconiosis. Am J Respir Crit Care Med 1996; 154: 741-748.

20. Remy-Jardin M, Remy J, Boulenguez C, Sobaszek A, Edme JL, Furon D. Morphologic effects of cigarette smoking on airways and pulmonary parenchyma in healthy adult volunteers: CT evaluation and correlation with pulmonary function tests. Radiology 1993; 186: 107-115.

21. Remy-Jardin M, Remy J, Gosselin B, Becette V, Edme JL. Lung parenchymal changes secondary to cigarette smoking: pathologic-CT correlations. Radiology 1993; 186: 643-651.

22. Collins LC, Willing S, Bretz R, Harty M, Lane E, Anderson WH. High-resolution CT in simple coal worker's pneumoconiosis. Chest 1993; 104: 1156-1162.

23. Morgan MDL. Detection and quantification of pulmonary emphysema by computed tomography: a window of opportunity. Thorax 1992; 47: 1001-1004.

24. Müller NL, Thurlbeck WM. Thin-section CT, emphysema, air trapping, and airway obstruction. Radiology 1996; 199: 621-622.

25. Parkes WR. Pneumoconiosis associated with coal and other carbonaceous materials. In: Parkes WR, ed. Occupational Lung Disorders. Oxford, Butterworth-Heinemann, 1994; pp. 340-410.

26. Van Muylem A, De Vuyst P, Yernault JC, Paiva M. Inert gas single-breath washout and structural alteration of respiratory bronchioles. Am Rev Respir Dis 1992; 146: $1167-1172$.

27. Churg A, Wright JL, Wiggs B, Pare PD, Lazar N. Small airways disease and mineral dust exposure: prevalence, structure and function. Am Rev Respir Dis 1985; 131: 139-143.

28. Nemery B, Brasseur L, Veriter C, Frans A. Impairment of ventilatory function and pulmonary gas exchange in nonsmoking coal miners. Lancet 1987; ii: 1427-1430. 